\title{
JOVENS ESTUDANTES UNIVERSITÁRIOS/AS PERANTE A FUTURA VIDA PROFISSIONAL E FAMILIAR: A MARCA DO GÉNERO
}

\section{Resumo}

A informação recolhida através de um inquérito por questionário aplicado a jovens universitários/as permitiu verificar que os jovens universitários têm melhores perspetivas em relação à inserção laboral e à carreira profissional do que as jovens universitárias. No contexto de crise laboral, foram mais as jovens mulheres, contrariamente aos seus colegas do sexo masculino, a condicionar os seus projetos familiares devido às fracas perspetivas de inserção laboral. São ainda as jovens que apresentam os valores e as atitudes mais igualitárias e progressistas relativamente aos papéis de género na vida profissional e familiar. Relativamente à questão da articulação entre o domínio profissional e o laboral, são valorizadas práticas de organização do trabalho e políticas de gestão dos recursos humanos amigas das famílias. Contudo, são as jovens mulheres quem mais confere relevância às mesmas.

Palavras-chave: Estudantes universitários/as, aspirações profissionais, articulação trabalho-família, papéis de género.

\section{Abstract}

Undergraduate students' in face of their future professional career and family life

The data collected through a questionnaire survey applied to undergraduate students illustrate that male students have better perspectives of integration in the labour market and concerning their professional careers than female students. In a context of labour market crisis, the survey results show that young women are more likely than their male counterparts to limit their family projects due to their poor labour perspectives. Young women are also the ones displaying more egalitarian values and attitudes, and the ones that are more progressive in relation to gender roles in both professional and family lives. Furthermore, the results confirm that students tend to value work organization practices and human resources management policies that are family friendly. Nonetheless, the study shows that young women give more relevance to such policies and practices than their male counterparts. roles.

Keywords: Undergraduate students, career aspirations, work-family balance, gender

\footnotetext{
* Instituto Superior de Economia e Gestão, Universidade de Lisboa (ISEG-ULisboa)

Endereço eletrónico: sofiacoelho_92@hotmail.com

Endereço postal: Instituto Superior de Economia e Gestão, Universidade de Lisboa (ISEG-ULisboa), Rua do Quelhas, n. ${ }^{\circ}$ 6, 1200-781 Lisboa, Portugal

** Instituto Superior de Economia e Gestão, Universidade de Lisboa (ISEG-ULisboa)

Endereço eletrónico: sarafc@iseg.ulisboa.pt
} 


\begin{abstract}
Résumé
Les jeunes universitaires face à la future vie professionnelle et familiale: la marque du genre

L'information recueillie à travers une enquête par questionnaire auprès des étudiant-e-s de l'enseignement supérieur ont démontré que ce sont les étudiants, plutôt que les jeunes étudiantes, qui ont de meilleures perspectives de s'intégrer sur le marché de travail et d'avoir accès à une carrière professionnelle. Par ailleurs, dans un contexte de crise du marché de travail, les jeunes étudiantes sont plus susceptibles de limiter leurs projets familiaux en fonction de leurs mauvaises perspectives d'emploi. De surcroit, elles affichent des valeurs et des comportements beaucoup plus égalitaires, ainsi qu'une disposition plus progressiste sur les rôles liés au genre, dans leurs vies professionnelles et familiales. En ce qui concerne l'organisation du plan professionnel, les deux sexes ont tous tendance à valoriser pratiques d'organisation du travail et politiques de gestion des ressources humaines favorables à la famille, même si elles accordent plus d'importance à ces pratiques.
\end{abstract}

Mots-clés: Etudiant(e)s de l'enseignement supérieur, aspirations professionnelles, équilibre travail-famille, rôles liés au genre.

\title{
Introdução
}

Este artigo centra-se na população jovem universitária, observando os seus valores, atitudes, expectativas e aspirações relativamente à futura vida profissional e familiar. Reflete, também, sobre as suas representações quanto aos papéis de género ideais numa relação de conjugalidade. A discussão apoia-se nos dados resultantes de um inquérito por questionário aplicado a finalistas do curso de Gestão do Instituto Superior de Economia e Gestão (ISEG), da Universidade de Lisboa. Neste contexto, as implicações da crise financeira e económica no mercado de trabalho estavam particularmente presentes, sendo o aumento do desemprego na população jovem, fundamentalmente em 2012 e 2013, um dos temas mais prementes no debate académico e social. Simultaneamente, o Governo português anunciava a apresentação de um plano de ação de incentivo à natalidade, tendo adjudicado um estudo orientado para esse fim. Posto este cenário, propusemo-nos explorar as seguintes questões: a) De que modo é que as perspetivas quanto à inserção laboral e profissional no atual contexto de crise económica e laboral influem nos projetos familiares futuros (de maternidade/paternidade) das/ os jovens finalistas universitárias/os? b) Em que medida é que os jovens e as jovens partilham de iguais valores, atitudes, expectativas e aspirações relativamente à vida profissional e familiar futura? c) Como são perspetivadas as políticas e práticas empresariais de articulação trabalho-família? d) Que recomendações podem ser formuladas, a partir dos resultados, no plano das políticas e programas de formação superior em particular e da transversalização da perspetiva de género nas políticas públicas em geral?

Ainda que o tema dos valores e das atitudes da população jovem relativamente ao trabalho profissional e à família, à luz de uma perspetiva analítica de 
género, tenha sido objeto de aprofundamento no campo científico nacional, a verdade é que pouco se sabe sobre a população universitária em particular, e menos ainda sobre as questões que aqui perscrutamos. Uma vez que o tema entrecruza várias áreas de estudo, remetendo para um debate científico internacional amplo, procuramos refletir especificamente sobre o contributo da nossa investigação para o aprofundamento dos Estudos do Género no contexto nacional. O grupo observado é particularmente pertinente, dada a aproximação à entrada no mercado de trabalho e ao início do desenvolvimento de uma carreira profissional. Acresce relevância o facto de o contexto do estudo ser uma instituição do ensino superior na área da Economia e da Gestão, em que se procura desenvolver formação que capacite as alunas e os alunos para a liderança de empresas e organizações em geral, para a inovação e o empreendedorismo. ${ }^{1}$ Sendo conhecida a sub-representação de mulheres nestas áreas da vida económica e empresarial, a informação obtida pode informar e qualificar as políticas em domínios diversos - desde logo, as políticas e os programas internos da instituição onde decorreu o estudo, promovendo a transversalização de uma perspetiva de género nos currículos formativos (Alvarez e Vieira 2014; Pinto 2010). Depois, pode ser útil ao desenho das políticas públicas no domínio da educação, ensino superior e ciência (Ferreira et al. 2010). Por fim, pode ainda ser útil ao desenvolvimento de projetos de investigação-ação orientados para a desconstrução de conceções estereotipadas em torno dos papéis de género e para a promoção, junto das jovens em particular, de aspirações de liderança no universo empresarial e económico.

\section{A pertinência do tema no contexto atual e o debate científico nacional}

A temática relativa aos valores e atitudes da população jovem face ao trabalho profissional e à família, à luz de uma perspetiva analítica de género, já foi objeto de estudo no campo científico nacional (e.g. Torres et al. 2006; Aboim 2007, 2010; Wall et al. 2016); no entanto, ainda pouco se sabe sobre a população universitária em particular (Amâncio 1992; Coimbra, Andrade e Fontaine 2001; Casaca e Chagas Lopes 2011; Sales Oliveira e Villas-Boas 2012), e menos ainda sobre as questões que aqui perscrutamos. Com efeito, aprofundar o conhecimento sobre o que pensam as/os jovens em idade adulta acerca das suas oportunidades de inserção laboral e de desenvolvimento profissional, assim como sobre a relação entre as suas expectativas e aspirações neste domínio e aquelas que se prendem com os projetos de vida familiar, incluindo a maternidade e paternidade, afigurase fundamental para a compreensão do puzzle complexo de fatores que estruturam, produzem e reproduzem fenómenos de segregação sexual no mercado de trabalho.

Como consta do sítio na Internet da instituição relativamente à sua Missão e Valores. Disponível em https://aquila4.iseg.ulisboa.pt/aquila/instituicao/ISEG/quem-somos/missao-e-valores. 
O estudo decorreu num contexto de profundas reformas laborais, na sequência do memorando de entendimento assinado entre o Governo português e as instituições que constituíram a designada Troika - o Fundo Monetário Internacional (FMI), o Banco Central Europeu (BCE) e Comissão Europeia (CE) (Addabbo et al. 2015; Ferreira 2014). Neste período, agravou-se a vulnerabilidade à condição de desemprego, o emprego instável e precário e o trabalho a tempo parcial involuntário, sobretudo em 2012 e 2013. É entre a população mais jovem que a precariedade é mais acentuada, abrangendo mais de dois terços da população empregada com idades compreendidas entre os 15 e os 24 anos, tendo atingido o valor mais elevado em 2015 (69,7\% e 65,6\% no caso das e dos jovens, respetivamente). ${ }^{2}$ É também de sublinhar que a taxa de desemprego mais elevada se regista entre as camadas mais jovens, tendo-se aproximado de $40 \%$ em 2013, sobretudo no caso das mulheres $(39,6 \%)$ e ligeiramente menos no caso dos homens $(36,7 \%){ }^{3}$

Os estudos têm comprovado que o investimento na escolaridade não está a produzir efeitos significativos na melhoria da inserção laboral dos jovens e das jovens portuguesas, especialmente no que se refere aos/às que detêm uma licenciatura (Gonçalves 2010; Oliveira e Carvalho 2010; Carmo, Cantante e Alves 2014). Como se tem feito referência, um dos traços mais característicos da vivência juvenil consiste em adiar projetos pessoais, incluindo formular projetos autónomos de vida (Guerreiro e Abrantes 2007; Kovács e Chagas Lopes 2012). A elevada precariedade contratual não é alheia às baixas taxas de natalidade - que, aliás, colocam em causa a reposição geracional (o índice sintético de fecundidade registaria, também em 2013, o valor mais baixo de sempre -1,214) (Cunha 2014). Em geral, os/ as jovens não recusam a ideia de ter filhos/as; no entanto, a decisão decorre cada vez mais de uma opção programada, a ter lugar quando as condições económicas se afiguram as adequadas a proporcionar-lhes qualidade de vida (Coimbra, Andrade e Fontaine 2001; Almeida 2003). É de notar, ainda, que as mulheres são frequentemente penalizadas pela maternidade - seja enquanto condição real ou eventual, num contexto marcado por modelos de organização do trabalho e práticas de gestão pouco amigas das pessoas com responsabilidades familiares. A este respeito, saliente-se a cultura das longas horas de trabalho ou a irregularidade de horários, contraindo o tempo para a vida familiar e pessoal (Casaca 2013). No caso da população jovem que entra no mercado de trabalho, esta situação agrava-se particularmente; em contextos de elevada competitividade, os/as jovens praticam longas jornadas de trabalho para mostrar o seu «compromisso» com a entidade empregadora, na tentativa de conseguir uma relação laboral mais estável (Guerreiro e Abrantes 2007; Cabral 2011).

2 Eurostat, Labour Force Survey. Disponível em: http://ec.europa.eu/eurostat/data/database [Consultado em 2 de maio de 2017].

3 Embora com declínio nos ano seguintes $-29,8 \%$ e $27,2 \%$ no caso das mulheres e dos homens jovens, em 2016 (INE, 2017).

4 Pordata. Disponível em: http://www.pordata.pt/Portugal/Indicadores+de+fecundidade+Índice+ sintético+de+fecundidade+e+taxa+bruta+de+reprodução-416 [Consultado em 2 de maio de 2017]. 
Esta referência à relação trabalho-família é indissociável da análise das representações em torno dos papéis de género. No que se refere às alterações no plano dos valores e das atitudes, a literatura evidencia que a população portuguesa, sobretudo a mais jovem, se revela menos institucionalista em relação ao casamento e à divisão sexual do trabalho, reconhecendo tanto o direito das mulheres à participação no mercado de trabalho e na esfera pública em geral como a importância da participação masculina na esfera privada. Os valores mais modernistas são mais partilhados pelas mulheres do que pelos homens, sendo mais expressivos quando se trata de pessoas com graus de escolaridade superior e mais jovens (Aboim 2007, 2010). Esta tendência é igualmente verificada no que toca às representações da maternidade e da paternidade, destacando-se uma crescente disseminação de uma masculinidade cuidadora, indiciadora de uma transformação nos papéis de género na família, no sentido de um maior equilíbrio, e consolidada no usufruto das licenças parentais pelos homens e na valorização que atribuem a políticas de articulação trabalho-família (Wall et al. 2016).

Retomando o mercado de trabalho em geral, é ainda de reter que as assimetrias salariais em desfavor das mulheres se têm mantido praticamente inalteradas e que são diretamente proporcionais aos níveis de escolaridade e de qualificação (Gonzaléz, Santos e Santos 2009; Ferreira 2010; Casaca e Perista 2014). No domínio da liderança da vida empresarial, a sub-representação feminina nos lugares de topo das empresas remete Portugal para uma das posições mais críticas de todo o espaço europeu (Casaca 2014). Pouco se sabe, porém, quanto às aspirações das/ os jovens relativamente à carreira profissional. Sem adotar uma perspetiva individualista, próxima das teses do capital humano, da agência e das preferências individuais, importa indagar se há um diferencial atitudinal entre mulheres e homens - exposto, no caso delas, numa menor orientação para o investimento na vida profissional, em menores níveis de ambição em termos de carreira e de confiança quanto ao potencial de liderança. Interessa-nos, pois, questionar se a socialização especializada em função do género está refletida nas atitudes e aspirações individuais relativamente à vida profissional e familiar e se potencia desigualdades nos percursos profissionais e de vida entre as/os jovens de ambos os sexos.

\section{Análise e discussão de resultados}

\section{Opções metodológicas e caracterização da amostra}

Procurou-se desenvolver um estudo relativamente extensivo que abrangesse a população finalista do curso de Gestão do ISEG, sujeitando-a a uma bateria vasta de questões relativas às perspetivas laborais, profissionais, familiares e aos papéis de género. Esta opção permitiu traçar um diagnóstico da posição das jovens e dos jovens inquiridas/os relativamente às questões selecionadas, em sintonia com os objetivos centrais da investigação (ver Introdução). A finalização 
desta fase do estudo não deixa, porém, de estimular investigações futuras que, alicerçadas numa metodologia de natureza qualitativa, permitam aprofundar algumas das conclusões e reflexões aqui exploradas. Será certamente um outro estudo, orientado por outras questões e objetivos e ancorado numa abordagem mais compreensiva.

Importa também referir que, em linha com o enquadramento teórico o estudo filtrou variáveis de análise e adiou a inclusão de outras para estudos subsequentes. Assim se justifica a opção por atender às perspetivas em torno de uma futura maternidade/paternidade, num contexto profundamente marcado pelo debate em torno da preocupante baixa de natalidade e da elevada precariedade laboral, não obstante a relevância de dimensões importantes dos projetos familiares que importa futuramente observar. De igual modo, se aqui nos centrámos nas perspetivas em torno das configurações familiares dominantes e a papéis de género no quadro de uma relação de casal heterossexual, estamos conscientes da necessidade de aprofundar os valores, as atitudes e aspirações dos/as jovens relativamente a outros modelos afetivos e familiares. Seria portanto interessante, numa segunda fase, realizar um estudo compreensivo e ainda mais abrangente que atendesse a matérias aqui não perscrutadas: no domínio laboral e profissional, a visão das/ os jovens sobre a liderança, as perspetivas em torno de políticas e medidas promotoras de uma maior igualdade de género no acesso ao emprego e nas carreiras profissionais, da paridade nos lugares de direção; e no domínio familiar, as suas perceções em torno da possível necessidade de assistir e cuidar de ascendentes (pessoas idosas), as suas representações em torno do casamento/coabitação, das várias formas de conjugalidade e de configurações familiares-afetivas.

Como referido, a investigação privilegiou o método quantitativo, tendo, para o efeito, procedido à aplicação de um inquérito por questionário e à análise dos dados respetivos, com recurso ao programa SPSS (Statistical Package for Social Sciences). Para aferir as atitudes face à vida familiar, recorreu-se à estrutura de questões do ISSP (International Social Survey Programme) (cf. Aboim 2007). O estudo abrangeu alunos/as finalistas que frequentavam o terceiro ano de Gestão do ISEG em 2014-2015, sendo a amostra não probabilística e assente no método ocasional de amostragem. O questionário foi aplicado a todas/os as/os alunas/os que frequentaram as aulas práticas de uma unidade curricular (UC) obrigatória do $3 .^{\circ}$ ano do programa curricular de Gestão. ${ }^{5}$ Estavam inscritos/as 291 alunos/as, mas foram inquiridos/as aqueles/as que, na semana de inquirição, frequentaram as respetivas aulas práticas. A aplicação do questionário ocorreu em dezembro de 2014. A colaboração dos/as alunos/as e a disponibilidade de alguns professores e professoras possibilitou a respetiva aplicação em tempo de aulas, por administração direta. A amostra integrou 100 estudantes, sendo 53 do sexo feminino e 47 do sexo masculino, registando uma média de 21 anos (a pessoa com mais idade tinha, à data, 31 anos). Praticamente

Alunos/as de outras licenciaturas - Finanças, Economia e Matemática Aplicada à Economia e à Gestão - podem frequentar a respetiva UC como optativa, mas o número é residual. 
todas as pessoas inquiridas (99) se identificaram como sendo solteiras/os; apenas uma assinalou o estado de "casado/a/união de facto». Praticamente três quartos destas/es jovens residem com a família de origem, as/os demais vivem com colegas, amigas/os ou outros familiares. Apenas uma pessoa vive com o/a companheiro/a.

\section{Orientações relativamente à vida laboral e profissional}

Em relação à inserção laboral, $41 \%$ dos/as universitários/as mostraram-se confiantes em conseguir uma colocação no mercado de trabalho na respetiva área de formação, no prazo máximo de três meses após a conclusão do curso. Com este grau de confiança encontrava-se um terço das mulheres e mais de metade dos homens inquiridos.

No caso das jovens, tudo indica que o projeto de maternidade parecia estar condicionado quando as expectativas de inserção estável no mercado laboral eram fracas - ou seja, sempre que se considera que a tentativa de obtenção do primeiro emprego pode ser superior a 12 meses. No caso dos jovens, a paternidade não está (estatisticamente) associada às expectativas laborais. ${ }^{6}$ Ainda assim, é de reter que a «dificuldade em conseguir emprego estável» é, independentemente do sexo, um dos fatores mais apontados para que não seja equacionada, no futuro, a maternidade/paternidade.

No que diz respeito às remunerações a auferir nessa primeira colocação, cerca de dois terços $(65,4 \%)$ das jovens espera ganhar menos de 900 euros, enquanto menos de metade $(48,9 \%)$ dos jovens espera ganhar esse mesmo valor. Quando questionados/as sobre a remuneração que esperam auferir cinco anos depois de terem iniciado a atividade profissional, a referência que assume maior expressão é o escalão «1200-1500 euros». É de notar, porém, que cerca de 13\% dos/as jovens esperam alcançar, no prazo de cinco anos, o escalão mais elevado elencado no guião de questionário (mais de 3000 euros mensais); destes, $6 \%$ são do sexo feminino e $19 \%$ do sexo masculino.

Em relação aos horários de trabalho, questionámos os/as universitários/as sobre «quantas horas desejam trabalhar por semana». A maioria, independentemente do sexo, deseja vir a trabalhar a tempo inteiro, num horário inferior a 40 horas. Contudo, quando questionados/as sobre «quantas horas pensam efetivamente vir a trabalhar», cerca de três quartos $(77 \%)$, independentemente do sexo,

Procurámos, portanto, determinar se o tempo que os/as jovens anteveem que poderá decorrer entre o fim do curso e o primeiro emprego (inserção laboral) está estatisticamente associado aos seus projetos familiares (incluindo o de maternidade ou paternidade). Os resultados do coeficiente de contingência (CC) mostram que, para as jovens, o valor do CC é 0,495 com p=0,023; logo, podemos argumentar que as variáveis estão estatisticamente relacionadas; ou seja, existe associação entre as respostas das jovens universitárias, o tempo esperado para a inserção laboral e o seu desejo de serem mães. Para os inquiridos do sexo masculino, o valor do CC é 0,291, e o p-valor a considerar é $0,695>0,05$, o que indica que as variáveis não estão estatisticamente associadas. 
refere «mais de 41 horas semanais». Existe, portanto, uma discrepância entre aquilo que os/as jovens desejam e aquilo que antecipam como a realidade em matéria de tempos de trabalho, provavelmente na sequência de informações partilhadas por outros/as jovens já a exercer uma atividade profissional.

Ainda no que diz respeito às expectativas relativamente à sua carreira profissional, $81 \%$ dos jovens confiam muito/bastante numa carreira profissional promissora; a percentagem é inferior no caso das jovens: apenas cerca de $60 \%$ respondem no mesmo sentido (ver Quadro 1).

Em termos de liderança, $87 \%$ das estudantes esperam vir a exercer funções nesse domínio, aproximando-se do sentido da resposta dada por $92 \%$ dos colegas sexo masculino. Mas, quando questionadas/as se esperam (ou não) atingir um lugar de topo ao longo da sua carreira, mais de metade (62\%) mostra-se confiante, respondendo afirmativamente e com reconhecimento das dificuldades («sim, mas vai ser difícil»). Dentro deste grupo, a maioria é do sexo feminino, o que nos indica que são também as jovens aquelas que apresentam menores expectativas em termos de progressão de carreira. Praticamente um/a em cada três jovens (31\%) refere estar muito confiante em atingir um lugar de topo; dentro deste grupo, a maioria é do sexo masculino (ver Quadro 1).

\section{Quadro 1}

Aspirações dos/as jovens quanto à carreira profissional, por sexo

\begin{tabular}{lrrrr}
\hline & Mulheres & \multicolumn{2}{c}{ Homens } \\
& \multicolumn{1}{c}{$\%$} & $\mathrm{n}$ & \multicolumn{1}{c}{$\%$} & $\mathrm{n}$ \\
\hline Confia numa carreira promissora para si? & & & & \\
Muito/bastante & 60,4 & 32 & 80,9 & 38 \\
Mais ou Menos & 35,8 & 19 & 10,6 & 5 \\
Pouco & 3,8 & 2 & 8,5 & 4 \\
Total & 100,0 & 53 & 100,0 & 47 \\
\hline Vê-se a exercer funções profissionais & & & & \\
de liderança, no futuro? & 86,8 & 46 & 91,5 & 43 \\
Sim & 13,2 & 7 & 8,5 & 4 \\
Não & 100,0 & 53 & 100,0 & 47 \\
\hline Total & & & & \\
\hline Vê-se a exercer um lugar de gestão de topo, no futuro? & 22,6 & 12 & 40,4 & 19 \\
\hline Sim, estou muito confiante que assim será & 69,8 & 37 & 53,2 & 25 \\
Sim, mas vai ser difícil & 7,5 & 4 & 6,4 & 3 \\
\hline Não & 100,0 & 53 & 100,0 & 47 \\
\hline Total & & &
\end{tabular}

Nota: Por questões de arredondamento, os totais podem não corresponder à soma das parcelas. 
Esta informação parece refletir um fosso em termos de confiança e de aspirações entre mulheres e homens, em desfavor delas - dimensão que remete para um espaço de intervenção, por preencher, no sentido de capacitar (empoderar) as jovens, estimulando a aspiração de empreender uma carreira profissional compatível com a ocupação de lugares estratégicos na vida empresarial e económica em geral. No caso delas, a ambição afigura-se mais atenuada, muito provavelmente em resultado do ajustamento ao «modo de ser» socialmente construído, ao passo que, no caso deles, a maior ambição conflui com a representação social dominante de masculinidade (Amâncio 1993).

A esmagadora maioria dos/as jovens inquiridos/as (93\%) considera que as políticas e práticas de articulação trabalho-família, em contexto profissional, deve dirigir-se a trabalhadores/as de ambos os sexos; ainda assim, é de reter que 13\% dos jovens do sexo masculino entendem que essas políticas e práticas devem ser exclusivamente orientadas para as trabalhadoras do sexo feminino. Nenhum/a jovem, porém, independentemente do sexo, selecionou a opção de reposta «as políticas de articulação trabalho-família devem ser direcionadas para trabalhadores do sexo masculino». Com o intuito de complementar esta observação, procurámos confirmar se a variável «sexo» está estatisticamente associada à posição dos/as jovens relativamente aos grupos-alvo das políticas de articulação trabalho-família. Para tal, efetuámos o teste exato de Fisher, ${ }^{7}$ que permitiu constatar a associação. Com efeito, as jovens universitárias $(98,1 \%)$, mais do que os seus colegas do sexo masculino $(87,2 \%)$, consideram que a implementação de políticas de articulação trabalhofamília deve ser direcionada para trabalhadores/as de ambos os sexos. É possível, assim, concluir, uma vez mais, que elas tendem a demonstrar valores e atitudes mais igualitárias relativamente aos papéis de género na vida profissional e na familiar.

Perguntámos aos/às jovens se consideram que as políticas de articulação trabalho-família, no contexto das futuras entidades empregadoras, podem ser cruciais na decisão de terem crianças. Mais de metade $(56 \%)$ responde afirmativamente, ainda que mais as mulheres $(60 \%)$. Num momento em que o país debate a baixa taxa de natalidade, esta conclusão deve elevar o sentido de responsabilidade social das empresas neste domínio (Casaca 2016). Praticamente um quarto das pessoas inquiridas afirma ainda não ter opinião formada sobre o assunto, sendo expectável que a perceção dos constrangimentos organizacionais à articulação trabalho-família se clarifique após a entrada no mercado de trabalho.

Orientações relativamente à vida familiar e representações sobre os papéis de género

Quanto à vida familiar - em particular os projetos no domínio da maternidade e paternidade -, a análise dos dados revela que a maioria dos/as jovens, inde-

$7 \quad$ Atendendo a que uma ou mais células apresentavam um valor esperado igual ou inferior a cinco, e quando a tabela em análise é 2 X2. Resultado: o p=0,049 $(<0,05)$. 
pendentemente do sexo, deseja vir a ser pai ou mãe. No caso das mulheres, esse é o desejo de $87 \%$ das inquiridas, sendo que apenas $4 \%$ respondem negativamente e $9 \%$ referem ainda não ter pensado no assunto. No caso dos homens, $85 \%$ confirmam desejar ser pais e apenas $4 \%$ afirmam não ter esse desejo (11\% referem não ter pensado no assunto). Dentro do grupo dos/as jovens que desejam vir a ser pais/ mães, a média de idades com que esperam vir a ter a primeira criança é muito próxima: 28,8 anos no caso delas e 28,7 anos no caso deles.

\section{Quadro 2}

Motivos que podem influenciar a decisão de não ter crianças

(ou de não ter o número de crianças que desejaria)

\begin{tabular}{lcccc}
\hline Sexo & $\begin{array}{c}\text { Custos financei- } \\
\text { ros associados }\end{array}$ & $\begin{array}{c}\text { Dificuldade em } \\
\text { conseguir emprego } \\
\text { estável }\end{array}$ & $\begin{array}{c}\text { Dificuldade de articula- } \\
\text { çada profissional } \\
\text { e familiar }\end{array}$ & $\begin{array}{c}\text { Investimento carreira } \\
\text { natissional } \\
\text { profiss }\end{array}$ \\
\hline Feminino & 4,26 & 3,98 & 3,45 & 3,19 \\
Masculino & 3,89 & 3,56 & 3,08 & 2,67 \\
\hline Total & 4,09 & 3,78 & 3,28 & 2,95 \\
\hline
\end{tabular}

Valores médios - 1: nada importante; 2: pouco importante; 3: mais ou menos importante; 4: bastante importante; 5: muito importante

\begin{tabular}{|c|c|c|c|c|}
\hline \multicolumn{5}{|c|}{ Estatísticas - Teste U de Mann-Whitney } \\
\hline & $\begin{array}{l}\text { Custos financei- } \\
\text { ros associados }\end{array}$ & $\begin{array}{c}\text { Dificuldade em } \\
\text { conseguir emprego } \\
\text { estável }\end{array}$ & $\begin{array}{c}\text { Dificuldade de articula- } \\
\text { ção da vida profissional } \\
\text { e familiar }\end{array}$ & $\begin{array}{c}\text { Investimento } \\
\text { na carreira } \\
\text { profissional }\end{array}$ \\
\hline U de Mann-Whitney & 587 & 585,5 & 610 & 563 \\
\hline Wilcoxon W & 1253 & 1251,5 & 1276 & 1229 \\
\hline $\mathrm{Z}$ & $-1,808$ & $-1,795$ & $-1,516$ & $-1,997$ \\
\hline $\begin{array}{l}\text { Significância Sig. } \\
\text { ( } 2 \text { extremidades) }\end{array}$ & 0,071 & 0,073 & 0,129 & 0,046 \\
\hline
\end{tabular}

A «realização pessoal» é identificada como um dos principais motivos para a decisão de ter filhos/as no caso das jovens inquiridas, contando com uma média de 4,13, numa escala de Likert 1 a $5 .{ }^{8}$ Por sua vez, aos jovens está associada uma média relativamente inferior $(4,05)$. O motivo que mais pode condicionar a decisão

8 Em que: 1 significa nada importante; 2 - pouco importante; 3 - mais ou menos importante; 4 - bastante importante; 5 - muito importante. 
de ter crianças (ver Quadro 2) prende-se com os custos financeiros que lhe estão associados, seguindo-se a dificuldade de conseguir um emprego estável, as dificuldades de articulação da vida profissional e familiar, e o investimento na carreira profissional. Note-se que são sempre as jovens a atribuir um grau de importância superior aos motivos elencados, sendo a diferença entre os sexos estatisticamente significativa no que se refere ao último motivo apresentado. Este resultado decorre, possivelmente, do facto de o desenvolvimento de uma carreira profissional e a maternidade serem percecionados como áreas potencialmente conflituantes.

Relativamente às representações em torno dos papéis de género tidos como ideais, no caso de equacionarem viver em casal e constituir família, praticamente a totalidade das jovens mulheres $(96 \%)$ revê-se num modelo mais igualitário em que «os dois elementos do casal têm, igualmente, uma profissão exigente e onde as tarefas domésticas e os cuidados com os/as filhos/as são igualmente distribuídos por ambos». Esta percentagem, porém, é claramente menor no caso dos jovens do sexo masculino (78\%). Neste caso, 9\% revê-se no modelo de «família onde o elemento do casal com um emprego menos exigente deve desempenhar a maioria das tarefas relacionadas com a casa e os/as filhos/as (não interessa se é homem ou mulher)». A percentagem de mulheres a responder neste sentido é de $4 \%$. É de notar que alguns estudantes do sexo masculino (7\%) consideram como modelo ideal a «família em que os dois elementos do casal têm, igualmente, uma profissão exigente e onde as tarefas domésticas e os cuidados com os/as filhos/as são sempre da responsabilidade da mulher», e igual percentagem identifica-se com o modelo de «família em que a mulher tem uma ocupação menos exigente que o marido e, por conseguinte, desempenha a maioria das tarefas relacionadas com a casa e com os filhos/as». Refira-se que todas as pessoas inquiridas se reviram nas opções relativas a uma futura relação de casal e a um dos modelos de família apresentados (à exceção da opção mais tradicionalista - «Modelo 5: família onde só o marido tem um emprego e a mulher é doméstica»). Considerando o enquadramento teórico explorado, apenas nos circunscrevemos às opções no quadro de uma relação heterossexual. Ainda assim, nenhum/a inquirido/a exprimiu a sua não identificação com as opções de reposta.

Quando procurámos explorar se existe independência ou associação estatística entre o sexo dos/as inquiridos/as e o modelo de família que idealizam, ${ }^{9}$ foi possível observar que há associação entre o modelo mais igualitário e o sexo feminino. No mesmo registo, quando confrontadas/os com a matriz de questões inspirada no ISSP (International Social Survey Programme), uma vez aplicado o Teste U de Mann-Whitney, apurámos diferenças significativas entre os sexos no caso das seguintes afirmações:

Para tal, procedemos à análise do coeficiente de contingência. $\mathrm{O}$ valor do $\mathrm{CC}$ é 0,283 . e $\mathrm{p}=0,025$ $(<0,05)$, indicando, portanto, que o tipo de modelo de família escolhido pelos/as jovens está estatisticamente associado ao sexo dos/as estudantes. 
- «Uma mulher que não queira pelo menos um filho/a é egoísta» (Mann-Whitney=853,5, p=0,003). A média de concordância do sexo masculino com esta afirmação é superior $(2,26)$ à do sexo feminino $(1,57)$;

- «Em geral, os homens devem fazer metade das tarefas domésticas» (Mann-Whitney=775, p=0,001). A média de concordância perante esta afirmação é superior no sexo feminino $(4,11)$ do que no sexo masculino $(3,19)$;

- «Uma mulher não deve deixar o trabalho pelo facto de ter uma criança» (Mann-Whitney=920, p=0,021); perante esta afirmação, o grau de concordância é superior no sexo feminino $(4,47)$ do que no sexo masculino $(3,81)$;

- «Quando ambos os pais trabalham a tempo inteiro, o desenvolvimento das suas crianças é afetado» (Mann-Whitney=701,5, p=0,000); os jovens do sexo masculino têm uma maior média de concordância com esta afirmação $(3,19)$ do que as jovens do sexo feminino $(2,62)$.

- «O trabalho doméstico é tão importante como o trabalho pago» (Mann-Whitney=796,5, p=0,000); as inquiridas do sexo feminino apresentam uma maior média de concordância com esta afirmação $(3,68)$ do que os inquiridos do sexo masculino (3,15);

- «Eu continuaria a trabalhar mesmo se pudesse receber um salário igual ao que recebo atualmente sem ter que trabalhar para isso» (Mann-Whitney=779, $\mathrm{p}=0,003$ ); as jovens, perante esta afirmação, apresentam um maior grau de concordância $(3,48)$ do que os jovens $(2,82)$;

- «Homens ambiciosos e bastante orientados para uma carreira não deveriam ter uma mulher que trabalhasse profissionalmente» (Mann-Whitney=954,5, $p=0,021$ ); o grau de concordância com esta afirmação é superior nos inquiridos do sexo masculino $(1,81)$ comparativamente com o sexo feminino $(1,28)$;

- «Só trabalhando as mulheres são verdadeiramente independentes» (Mann-Whitney=821, p=0,002); perante esta afirmação, a média de concordância é superior nas jovens $(3,99)$ comparativamente com a média de concordância do sexo masculino (3,00);

- «Ter uma carreira profissional é mais importante para um homem do que para uma mulher» (Mann-Whitney $=881, \mathrm{p}=0,008$ ); perante esta afirmação, a média do grau de concordância é maior nas respostas dadas por jovens do sexo masculino $(2,36)$ do que nas respostas dadas por jovens do sexo feminino $(1,83)$.

Assim, na linha de outros estudos anteriormente realizados (Aboim 2007), concluímos que, neste caso, são também elas - mais do que os seus colegas do sexo masculino - que mais apresentam valores e atitudes igualitárias e progressistas relativamente aos papéis de género na vida profissional e na familiar. 


\section{Reflexões finais}

Este artigo resulta de um estudo sobre estudantes universitários/as (finalistas), centrando-se nos valores, atitudes, expectativas e aspirações projetadas para a futura vida profissional e familiar. Foram também analisadas as suas representações quanto aos papéis de género que idealizam no caso de planearem um projeto de conjugalidade e de maternidade/paternidade.

Os resultados obtidos permitiram concluir que, no contexto de acentuada crise laboral em que decorreu a aplicação do inquérito por questionário, são particularmente as jovens estudantes universitárias que tendem a condicionar os seus projetos familiares devido às fracas perspetivas de inserção no mercado laboral. Os jovens do sexo masculino revelaram, a este respeito, melhores perspetivas em relação à sua inserção laboral e à carreira profissional.

No que se refere à vida familiar, os resultados sugerem que, apesar de se estar perante um grupo da população tendencialmente modernista e progressista, a verdade é que a marca das representações tradicionais em torno dos papéis de género ainda se faz notar. Não está, portanto, ultrapassada a ideologia de que são essencialmente as mulheres quem deve assegurar as funções do cuidar e, simultaneamente, as responsabilidades profissionais. Todavia, em linha com estudos anteriores (Aboim 2007, 2010), são as jovens inquiridas que mais refletem nas suas repostas valores e as atitudes mais igualitárias e progressistas relativamente aos papéis de género na vida profissional e familiar.

Procurámos também apreender o grau de relevância atribuído a políticas e práticas orientadas, nos contextos profissionais, para a articulação da vida profissional e familiar. Os resultados obtidos indicam que tanto as jovens finalistas como os seus colegas do sexo masculino tendem a valorizar políticas e práticas organizacionais amigas das famílias. Contudo, continuam a ser elas quem mais relevância lhes confere. Acresce que a maioria referiu a importância das mesmas na decisão de ter crianças. Esta constatação permite destacar a importância de políticas de gestão e de organização do trabalho humanistas e inclusivas, favoráveis à igualdade entre mulheres e homens e à articulação com a vida familiar e pessoal (Casaca 2016).

A «dificuldade em conseguir emprego estável» afigurou-se, também, um dos fatores mais apontados pelas/os jovens para, no futuro, adiarem (ou mesmo renunciarem) a um projeto de maternidade ou paternidade. Esta constatação permite, a nosso ver, enquadrar o tema da baixa natalidade do país na elevada precariedade e insegurança que caracteriza o mercado de trabalho português. Pese embora as alterações circunstanciais inerentes à recente crise financeira, económica e laboral - que atingiram, num primeiro momento, severamente a mão-de-obra masculina -, a verdade é que são dimensões que tendem a assumir particular expressão no universo feminino, incluindo na população jovem (e.g. Guerreiro e Abrantes 2007; Casaca 2012, 2016; Kovács e Chagas Lopes 2012; Ferreira 2014; Addabbo et 
al. 2015). Confere, de igual modo, relevância a políticas públicas orientadas para o combate à precariedade de emprego e para a igualdade entre mulheres e homens no mercado de trabalho.

É de notar a importância acrescida do contexto em que o estudo teve lugar: uma instituição do ensino superior orientada para o desenvolvimento de formação na área da Economia e da Gestão, procurando capacitar as alunas e os alunos para a liderança, para a inovação e o empreendedorismo. A informação recolhida acerca das menores aspirações das jovens relativamente aos seus colegas do sexo masculino no domínio laboral e profissional deveria possibilitar a revisão das políticas da instituição e dos conteúdos programáticos. A intervenção poderia ter lugar no quadro da unidade curricular «Desenvolvimento Pessoal», ${ }_{10}^{10}$ por via de cursos livres e atividades extracurriculares promotoras da desconstrução de estereótipos de género e da promoção de valores e atitudes progressistas quanto ao lugar das mulheres e dos homens na esfera pública e privada. Esta linha de atuação deveria, igualmente, compreender a capacitação (ou empoderamento) das jovens, eliminando o fosso de confiança e «aspiracional» quanto à possibilidade de assumir lugares estratégicos. Trata-se, no fundo, de potenciar um contexto formativo que possibilite que as jovens e os jovens «incorporem o mesmo direito à escolha do seu percurso escolar, da sua profissão e do seu projeto de vida» (Alvarez e Vieira 2014, 14).

Esta recomendação não se aproxima, porém, dos pressupostos avançados pelas abordagens mais individualistas, dado que não ignora os condicionalismos estruturais e organizacionais. No plano destes últimos, é fundamental rever os modelos e as culturas de organização do trabalho, as normas, os valores, as narrativas, as práticas e as rotinas (formais e informais), os símbolos e a linguagem, as políticas e os procedimentos internos, as orientações da gestão, as representações sociais dominantes em torno dos papéis de género - no fundo, todos os elementos que constituem barreiras (incluindo as invisíveis) e que sustentam o «teto de vidro». Uma Escola Superior de Economia e Gestão é, também, um espaço privilegiado de intervenção, cabendo-lhe, igualmente, a responsabilidade de apoiar as alunas e os alunos (futuras gestoras e gestores) no desenho dos novos modelos de organização do trabalho e culturas organizacionais inclusivas (Casaca 2016).

Não obstante a mais-valia no plano da análise descritiva e comparativa que este estudo permite, seria muito importante não só incluir outras universidades como também integrar uma metodologia de análise qualitativa que permitisse

10 É de reter os objetivos desta UC: «1) A frequência dos cursos livres visa proporcionar aos alunos o aprofundamento e a actualização de competências e capacidades em áreas do conhecimento consideradas necessárias e complementares à formação de base. 2. O reconhecimento e a validação das actividades extra-curriculares, desenvolvidas fora do contexto de ensino formal, visam estimular os alunos a adquirirem, de forma diversificada, conhecimentos e competências sociais, relacionais, culturais e profissionais». Disponível em: https://aquila.iseg.utl.pt/aquila/getFile. do?method=getFile\&fileId=85081 [Consultado em 5 de maio de 2017]. 
aprofundar o tema em discussão. A informação recolhida permite, ainda assim, alertar para a necessidade de qualificar as políticas públicas no domínio da educação, ensino superior e ciência, atendendo em particular à relação com as instituições de ensino superior na transversalização da perspetiva de género. A este respeito, importa ter presente a capacidade transformadora e emancipatória do sistema educativo. A desconstrução das conceções tradicionais sobre liderança, cuidado, família, masculinidade e feminilidade deve ser potenciada ao longo de todo o ciclo educativo, desde o pré-escolar à formação pós-graduada (Alvarez e Vieira 2014).

\section{Referências bibliográficas}

Aboim, Sofia. 2007. «Clivagens e continuidade de género face aos valores da vida familiar em Portugal e noutros países da Europa». In Familia e Género em Portugal e na Europa, coordenado por Karin Wall e Lígia Amâncio, 35-91. Lisboa: ICS.

Aboim, Sofia. 2010. «Género, família e mudança em Portugal». In A Vida Familiar no Masculino. Negociando Velhas e Novas Masculinidades, coordenado por Karin Wall, Sofia Aboim e Vanessa Cunha, 39-64. Lisboa: Comissão para a Igualdade no Trabalho e no Emprego. Disponível em: http://cite.gov.pt/asstscite/downloads/publics/A_vida_masculino.pdf

Addabbo, Tindara et al. 2015. «Gender and Labour in Times of Austerity: Ireland, Italy and Portugal in a Comparative Perspective». International Labour Review 154(4): 449-473. Doi: https://doi.org/10.1111/j.1564-913X.2015.00250.x

Almeida, Ana Nunes. 2003. «Família, conjugalidade e procriação: valores e papéis». In Valores Sociais: Mudanças e Contrastes em Portugal e na Europa, coordenado por Jorge Vala, Manuel Villaverde Cabral e Alice Ramos, 47-93. Lisboa: ICS.

Alvarez, Teresa, e Cristina C. Vieira. 2014. «O papel da educação no caminho que falta percorrer em Portugal na desconstrução dos estereótipos de género: breves reflexões». Exedra: 8-17. Disponível em: http://www.exedrajournal.com/?p=323

Amâncio, Lígia. 1992. «As assimetrias nas representações do género». Revista Crítica de Ciências Sociais 34: 9-22. Disponível em: http://www.ces.uc.pt/rccs/index.php?id=457

Amâncio, Lígia. 1993. «Género, representações e identidades». Sociologia - Problemas e Práticas 14: 127-140. Disponível em: http://sociologiapp.iscte-iul.pt/pdfs/26/261.pdf

Cabral, Arlinda. 2011. «Conciliação ou conflito entre o trabalho e as outras esferas da vida social na inserção profissional dos diplomados do ensino superior». International Journal Working Conditions (RICOT Journal) 1: 68-97. Disponível em: http://ricot.com.pt/ artigos/1/ACabral_68.97.pdf

Carmo, Renato Miguel, Frederico Cantante, e Nuno de Almeida Alves. 2014. «Time projections: Youth and precarious employment». Time \& Society 23 (3): 337-357. Doi: https:// doi.org/10.1177/0961463X14549505

Casaca, Sara Falcão. 2012. «Mercado de trabalho, flexibilidade e relações de género: tendências recentes». In Mudanças Laborais e Relações de Género: Novos vetores de (des)igualdade, coordenado por Sara Falcão Casaca, 9-47. Coimbra: Almedina/Fundação Económicas.

Casaca, Sara Falcão. 2013. «As novas dinâmicas laborais e os desafios da articulação com a vida familiar». Sociologia, Problemas e Práticas 72: 31-52. Doi: https://doi.org/10.7458/ SPP2013722617 
Casaca, Sara Falcão. 2014. «A Igualdade entre mulheres e homens e a tomada de decisão na esfera económica: o longo percurso dos instrumentos normativos». Revista do Centro de Estudos Judiciários 2014 (1): 173-199. Disponível em: http://cite.gov.pt/pt/destaques/ complementosDestqs/sarafalcao.pdf

Casaca, Sara Falcão. 2016. "Natalidade: a urgência do compromisso do mundo empresarial». In A(s) Problemática(s) da Natalidade em Portugal: uma questão social, económica e política, coordenado por V. Cunha et al., 219-223. Lisboa: Coleção Observatórios ICS 3.

Casaca, Sara Falcão, e Margarida Chagas Lopes. 2011. «Gender matters in scientific and technological fields: time as a biased resource». SOCIUS Working Paper, $n^{\circ} 6$. Disponível em: http://hdl.handle.net/10400.5/1138

Casaca, Sara Falcão e Heloísa Perista. 2014. Estudo Qualitativo a partir do I Relatório sobre diferenciações salariais por ramos de actividade. Comissão para a Igualdade no Trabalho e no Emprego. Disponível em: http://cite.gov.pt/asstscite/downloads/Estudo_Qualitativo.pdf

Chaves, Miguel, Madalena Ramos e Rio Santos. 2016. «Convergences and disparities of work orientations among recent graduates in Portugal». Sociologia, Problemas e Práticas 80: 9-29.

Coelho, Sofia. 2015. As Perspetivas dos/as jovens estudantes universitários/as em relação ao trabalho e à família - O caso dos/as estudantes do ISEG. Dissertação de Mestrado em Gestão de Recursos Humanos, ISEG, Universidade de Lisboa.

Coimbra, Susana, Cláudia Andrade, e Anne-Marie Fontaine. 2001. «Conciliation des rôles familiaux et professionnels: vision prospective d'étudiants universitaires», Actes $d u$ XIIe congrès de l'AIFREF, St. Sauveur des Monts, Québec, 18-21 abril 2001.

Cunha, Vanessa. 2014. «Quatro décadas de declínio de fecundidade em Portugal». In Inquérito à Fecundidade 2013, editado por Instituto Nacional de Estatística e Fundação Francisco Manuel dos Santos, 19-28. Lisboa: Instituto Nacional de Estatística/Fundação Francisco Manuel dos Santos. Disponível em: http://hdl.handle.net/10451/11514

Ferreira, Virgínia. 2010. «A evolução das desigualdades entre salários masculinos e femininos: um percurso irregular». In A Igualdade de Mulheres e Homens no Trabalho e no Emprego em Portugal, coordenado por Virgínia Ferreira, 139-190. Lisboa: CITE. Disponível em: http://cite.gov.pt/asstscite/downloads/publics/Igualdade_CITE_NET.pdf

Ferreira, Virgínia. 2014. «Employment and austerity: changing welfare and gender regimes in Portugal». In Women and Austerity. The Economic Crisis and the Future of Gender Equality, editado por Maria Karamessini e Jill Rubery, 207-227. London: Routledge.

Ferreira, Virgínia, Maria J. Silveirinha, Sílvia Portugal, Cristina Vieira, Rosa Monteiro, Madalena Duarte, e Mónica Lopes. 2010. Estudo de Avaliação do III Plano Nacional para a Igualdade - Cidadania e Género: Relatório Final para a CIG. Coimbra: Associação para a Extensão Universitária. Disponível em: https:/www.cig.gov.pt/wp-content/ uploads/2013/12/III_PNI_Cidadania_e_Genero_2007_2010_Relatorio_Externo_de_ Execucao.pdf

Gonçalves. Carlos Manuel. 2010. «Emprego dos licenciados universitários». In Desigualdades Sociais 2010 - Estudos e Indicadores, coordenado por Renato Miguel Carmo, 181-190. Observatório das Desigualdades.

González, Pilar, Luís Santos, e Maria Clementina Santos. 2009. «Education and gender wage differentials in Portugal: what can we learn from an age cohort analysis?» Education Economics 17 (2): 263-278. Doi: https://doi.org/10.1080/09645290802628437

Guerreiro, Maria das Dores, e Pedro Abrantes. 2007. Transições incertas. Os Jovens Perante o Trabalho e a Familia. 2. ${ }^{a}$ Edição. Lisboa: Comissão para a Igualdade no Trabalho e no Emprego. Disponível em: http://cite.gov.pt/imgs/downlds/Transicoes_Incertas.pdf 
INE. 2017. Inquérito ao Emprego - 2016. Lisboa: Instituto Nacional de Estatística.

Kovács, Ilona, e Margarida Chagas Lopes. 2012. «A juventude e o emprego: entre a flexibilidade e a precaridade». Mudanças Laborais e Relações de Género, coordenado por Sara Falcão Casaca, 51-86. Coimbra: Almedina.

Oliveira, Luísa, e Helena Carvalho. 2010. «Desigualdades geracionais: os jovens e a precariedade de emprego na UE». In Desigualdades Sociais 2010 - Estudos e Indicadores, coordenado por Renato Miguel Carmo, 191-198. Observatório das Desigualdades.

Pinto, Teresa (2010). «Género e educação: por uma educação de qualidade». In Guião de Educação Género e Cidadania - $3^{\circ}$ Ciclo, coordenado por Teresa Pinto, Conceição Nogueira, Cristina C. Vieira, Isabel Silva, Luísa Saavedra, Maria J. Silva, Paula Silva, TeresaCláudia Tavares e Vasco Prazeres, 8-9. Lisboa: Comissão para a Cidadania e Igualdade de Género. Disponível em: https://www.cig.gov.pt/wp-content/uploads/2016/07/3Ciclo_Versao_Digital_FinalR.pdf

Sales Oliveira, Catarina, e Susana Villas-Boas. 2012. «Igualdade de Género na Universidade da Beira Interior». ex aequo 25: 119-136. Disponível em: http://www.scielo.mec. pt/scielo.php?script=sci_arttext\&pid=S0874-55602012000100010

Torres, Anália, Rita Mendes, e Tiago Lapa. 2006. «Famílias na Europa». In Contextos e Atitudes Sociais na Europa, coordenado por Jorge Vala e Anália Torres, 97-141. Lisboa: ICS.

Wall, Karin et al. 2016. Livro Branco Homens e Igualdade de Género em Portugal. Lisboa: ICS-CITE. Disponível em http://cite.gov.pt/asstscite/images/papelhomens/Livro_Branco_ Homens_Igualdade_G.pdf

Sofia Coelho. Licenciada em Ciência Política pelo Instituto Superior de Ciências Sociais e Políticas e Mestre em Gestão de Recursos Humanos pelo Instituto Superior de Economia e Gestão, da Universidade de Lisboa (ISEG-ULisboa). Técnica Superior de Recursos Humanos numa IPSS. Endereço eletrónico: sofiacoelho_92@hotmail.com

Sara Falcão Casaca. Professora Associada com Agregação do Instituto Superior de Economia e Gestão, da Universidade de Lisboa (ISEG-ULisboa. Investigadora-integrada do Centro de Investigação em Sociologia Económica e das Organizações (SOCIUS) e Investigadora-colaboradora do CIEG - Centro Interdisciplinar em Estudos de Género. Tem investigado e publicado sobre: flexibilidade de emprego e de tempos de trabalho; desigualdades de género na esfera laboral; género, liderança e tomada de decisão na esfera económica; e articulação trabalho-família. Endereço eletrónico: sarafc@iseg.ulisboa.pt

Artigo recebido a 13 de maio de 2017 e aceite para publicação a 13 de setembro de 2017. 
